\title{
Thyroid Gland Carcinoma
}

National Cancer Institute

\section{Source}

National Cancer Institute. Thyroid Gland Carcinoma. NCI Thesaurus. Code C4815.

A carcinoma arising from the thyroid gland. It includes the following main subtypes:

follicular, papillary, medullary, poorly differentiated, and undifferentiated (anaplastic) carcinoma. 